\title{
Effect of calcination temperature on the structural, optical and magnetic properties of pure and Fe-doped $\mathrm{ZnO}$ nanoparticles
}

\author{
RAminder Preet Pal Singh ${ }^{1}$, I.S. Hudiara ${ }^{2}$, Shashi Bhushan Rana ${ }^{3, *}$ \\ ${ }^{1}$ Department of Electronics \& Communication Engineering, Desh Bhagat University, Mandi Gobindgarh, India \\ ${ }^{2}$ Chitkara University (Punjab Campus), Chandigarh, India \\ ${ }^{3}$ Department of Electronics \& Communication Engineering, GNDU Regional Campus, Gurdaspur, India
}

\begin{abstract}
In the present study, pure $\mathrm{ZnO}$ and $\mathrm{Fe}$-doped $\mathrm{ZnO}\left(\mathrm{Zn}_{0.97} \mathrm{Fe}_{0.03} \mathrm{O}\right)$ nanoparticles were synthesized by simple coprecipitation method with zinc acetate, ferric nitrate and sodium hydroxide precursors. Pure $\mathrm{ZnO}$ and Fe-doped $\mathrm{ZnO}$ were further calcined at $450{ }^{\circ} \mathrm{C}, 600{ }^{\circ} \mathrm{C}$ and $750{ }^{\circ} \mathrm{C}$ for $2 \mathrm{~h}$. The structural, morphological and optical properties of the samples were characterized by X-ray diffractometer (XRD), scanning electron microscope (SEM), energy dispersive spectroscopy (EDS) and UV-Vis absorption spectroscopy. The X-ray diffraction studies revealed that the as-synthesized pure and doped ZnO nanoparticles have hexagonal wurtzite structure. The average crystallite size was calculated using Debye-Scherrer's formula. The particle size was found to be in nano range and increased with an increase in calcination temperature. SEM micrographs confirmed the formation of spherical nanoparticles. Elemental compositions of various elements in pure and doped $\mathrm{ZnO}$ nanoparticles were determined by EDX spectroscopy. UV-Vis absorption spectra showed red shift (decrease in band gap) with increasing calcination temperature. Effect of calcination on the magnetic properties of Fe-doped $\mathrm{ZnO}$ sample was also studied using vibrating sample magnetometer (VSM). M-H curves at room temperature revealed that coercivity and remanent polarization increase with an increase in calcination temperature from $450{ }^{\circ} \mathrm{C}$ to $750{ }^{\circ} \mathrm{C}$, whereas reverse effect was observed for magnetization saturation.
\end{abstract}

Keywords: ZnO nanoparticles; co-precipitation; X-ray diffractometer; optical properties; UV-Vis absorption spectroscopy

(C) Wroclaw University of Technology.

\section{Introduction}

$\mathrm{ZnO}$ is a group II - IV semiconductor that has become one of the most promising candidates for potential applications in optoelectronics due to its wide band-gap $(3.3 \mathrm{eV})$ and high exciton binding energy $(60 \mathrm{meV})$ properties $[1,2]$. In order to optimize the structural, optical and magnetic properties of $\mathrm{ZnO}$, a number of experiments have been done by various researchers either by using different capping agents or by doping ions into the $\mathrm{ZnO}$ lattice. Physical and chemical properties of zinc oxide vary with respect to the morphology of nanostructures. Therefore, not only various synthesis methods but also the physical and chemical

*E-mail: shashi_rana12@yahoo.co.in properties of synthesized zinc oxide are to be studied with respect to its morphology [3].

Diluted magnetic semiconductors (DMS) have attracted much attention in recent years because they are the type of semiconductor in which fraction of host cations can be easily replaced by magnetic ions in fabrication of spintronics devices, such as spin valve transistor [4-7]. In the past few years, scientists have investigated the effect of $\mathrm{ZnO}$ nanoparticles doping with transition metals, such as $\mathrm{Fe}, \mathrm{Co}, \mathrm{Ni}$ and $\mathrm{Mn}$ [8-20]. Numerous theoretical explanations that have been proposed revealed that on doping $\mathrm{ZnO}$ nanoparticles with these transition elements results in dramatic changes in various luminescent and magnetic properties. These transition metals have been doped into the $\mathrm{ZnO}$ lattice to change the optical and magnetic properties, 
for the potential applications in spintronics devices, such as spin field effect transistor, gas sensor and quantum computers. In order to realize these objectives it is necessary to create $\mathrm{ZnO}$ based ferromagnetic materials, and understand their physical and structural properties. Experimental studies confirmed that the ferromagnetism strongly depends on synthesis technique and environmental conditions used for the preparation of the samples.

Most of the $\mathrm{ZnO}$ nanocrystals have been synthesized by traditional high temperature solid state reaction methods. However, these methods are time consuming and properties of the product cannot be controlled. $\mathrm{ZnO}$ nanoparticles can be prepared on a large scale at low cost by simple solution based methods, such as chemical co-precipitation, hydrothermal reaction, and sol-gel synthesis. In the present work, we have synthesized $\mathrm{ZnO}$ nanoparticles using co-precipitation method. This is a simple and low cost method that gives good yield of the end product and takes less time to prepare the nanoparticles. In this research work we have studied the effect of calcination temperature on the structural and optical properties of $\mathrm{ZnO}$ nanoparticles. Further, we have also studied the effect of calcination temperature on the structural, optical and magnetic properties of Fe-doped $\mathrm{ZnO}$ nanoparticles.

Organization of this research paper is summarized as follows: Section 1, illustrates the experimental procedure used to synthesize the $\mathrm{ZnO}$ nanoparticles, Section 2, describes the instrumentation used to characterize the structural, morphological and optical properties of $\mathrm{ZnO}$ samples. In Section 3, various results have been discussed in detail in terms of the nanoparticle properties, while the Section 4 concludes the paper.

\section{Experimental}

All the materials used in this work were of analytical reagent grade and were used without any further purification. In order to synthesize pure $\mathrm{ZnO}$ nanoparticles, zinc acetate $\left(\mathrm{Zn}\left(\mathrm{CH}_{3} \mathrm{COO}\right)_{2} \cdot 2 \mathrm{H}_{2} \mathrm{O}\right)$ was dissolved in distilled water and stirred for 1 hour. Aqueous solution of $\mathrm{NaOH}$ was added dropwise to the solution to maintain the $\mathrm{pH} \sim 10$. The solution was then stirred at room temperature for 4 hours followed by aging for $24 \mathrm{~h}$ at the same temperature. After the aging, precipitate that formed was filtered and washed several times and was finally calcined at $450{ }^{\circ} \mathrm{C}$, $600{ }^{\circ} \mathrm{C}$ and $750{ }^{\circ} \mathrm{C}$ for $2 \mathrm{~h}$. Similarly, in order to synthesize the $\mathrm{Zn}_{0.97} \mathrm{Fe}_{0.03} \mathrm{O}$ nanoparticles, the same steps have been followed, except adding ferric nitrate $\left(\mathrm{FeNO}_{3}\right)$, according to the calculated stoichiometric ratio.

\subsection{Characterization of pure and doped samples}

X-ray diffraction patterns of all the powder samples were recorded by a rotating angle X-ray diffractometer (Bruker AXS D8 Advance, Germany) equipped with a graphite monochromator and a mirror, at a fixed incidence angle of $1^{\circ}$ to $5^{\circ}$ and $\mathrm{CuK} \alpha$ (wavelength $=1.540 \AA, 40 \mathrm{kV}$, $100 \mathrm{~mA}$ ) radiation source. The angular accuracy of the setup was $0.001^{\circ}$ and the angular resolution was about $0.01^{\circ}$. The samples were scanned in an angular direction in the range of $20^{\circ}$ to $90^{\circ}$

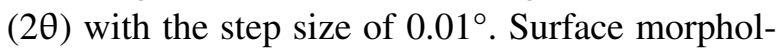
ogy of undoped (pure) and doped synthesized samples was determined by using scanning electron microscope Carl Zeiss Supras 55 which operated at a high acceleration voltage of $15 \mathrm{kV}$. The UV absorption spectra of the samples were recorded on the Systronics-2205 double beam spectrophotometer having a bandwidth of $1 \mathrm{~nm}$ and wavelength range of $200 \mathrm{~nm}$ to $1100 \mathrm{~nm}$. Elemental composition of various samples was determined by EDS spectroscopy at an acceleration voltage of $200 \mathrm{keV}$. Magnetic hysteresis loop at room temperature was measured by using a vibrating sample magnetometer (VSM, Microsense EZ9) with a maximum magnetic field strength of $22.5 \mathrm{kOe}$.

\section{Results and discussions}

\subsection{XRD analysis}

Fig. 1 shows X-ray diffraction patterns of the synthesized pure $\mathrm{ZnO}$ samples calcined at different temperatures. Each XRD sample exhibits 
a hexagonal wurtzite phase. In all the samples peak intensity is very high which confirms good crystalline formation. It is clear from the XRD patterns that all the characteristic diffraction peaks can be indexed to the diffractions of $\left(\begin{array}{lll}1 & 0 & 0\end{array}\right),\left(\begin{array}{lll}0 & 0 & 2\end{array}\right)$, (lll $\left.\begin{array}{lll}1 & 1\end{array}\right),\left(\begin{array}{lll}1 & 0 & 2\end{array}\right),\left(\begin{array}{lll}1 & 1 & 0\end{array}\right),\left(\begin{array}{lll}1 & 0 & 3\end{array}\right),\left(\begin{array}{lll}2 & 0 & 0\end{array}\right),\left(\begin{array}{lll}1 & 1 & 2\end{array}\right)$ and (2 0 1) planes with a hexagonal wurtzite structure. These diffraction peaks agree well with the values of the standard JCPDS No. 36-1451. XRD patterns clearly and show that the intensity of the peaks increases with an increase in calcination temperature, indicating increase in crystallinity at higher temperature.

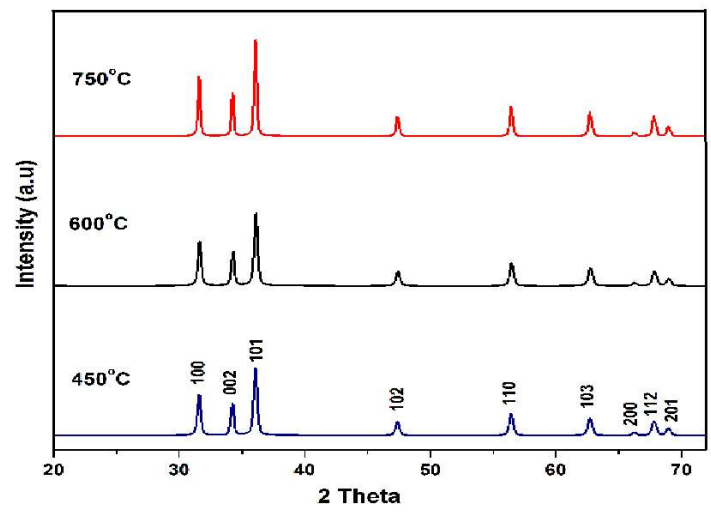

Fig. 1. XRD patterns of pure $\mathrm{ZnO}$ nanoparticles calcined at $450{ }^{\circ} \mathrm{C}, 600{ }^{\circ} \mathrm{C}$ and $750{ }^{\circ} \mathrm{C}$.

The average crystallite size was calculated by using Scherrer's equation 1 and was found to be in the range of $31 \mathrm{~nm}$ to $42 \mathrm{~nm}$ as shown in Table 1:

$$
\tau=\frac{k \lambda}{\beta \cos \theta}
$$

where $\tau$ is grain size, $\beta$ is the full width at half maximum, $\lambda$ is the wavelength of X-ray $(1.548 \AA$ ) and $\theta$ is the diffraction angle. From Table 1, it can be observed that the increase in particle size is significant at $750{ }^{\circ} \mathrm{C}$ as compared with the size at $600{ }^{\circ} \mathrm{C}$. Migration of grain boundaries occurs at higher temperature which results in coalescence of small grains and forming large grains.

From the d-spacing values, lattice constants ' $a$ ' and ' $c$ ' were calculated using equation 2 . The values are given in Table 1 :

$$
\frac{1}{d^{2}}=\frac{4}{3}\left(\frac{h^{2}+h k+k^{2}}{a^{2}}\right)+\frac{l^{2}}{c^{2}}
$$

The calculated lattice parameters were also in good agreement with the values reported in literature.

Fig. 2 shows X-ray diffraction patterns of Fe-doped $\mathrm{ZnO}$ nanoparticles calcined at $450{ }^{\circ} \mathrm{C}$, $600{ }^{\circ} \mathrm{C}$ and $750{ }^{\circ} \mathrm{C}$. Each XRD sample exhibits the hexagonal wurtzite phase without any impurities and the secondary phase which shows incorporation of $\mathrm{Fe}$ dopant into the $\mathrm{ZnO}$ wurtzite lattice as a substitute atom. The intensity of the peaks in the XRD pattern is similar to that of pure $\mathrm{ZnO}$, i.e. the peak intensity increases as the calcination temperature is increased. But, if we compare the corresponding peaks of pure and doped $\mathrm{ZnO}$ samples, it is observed that the intensity of doped samples decreases as compared to the pure samples. The further reveals that crystallinity reduces with the incorporation of $\mathrm{Fe}$ atoms into the $\mathrm{ZnO}$ lattice. It has been reported in literature that when a foreign particle is incorporated in a crystal lattice, it produces a strain as well as defects in the lattice which may deteriorate the crystal quality [21]. Table 2 summarizes the calculated average particle size and unit cell parameters. Average particle size varies from $29 \mathrm{~nm}$ to $38 \mathrm{~nm}$. Again the variation is similar to that in the pure $\mathrm{ZnO}$ nanoparticles but the only difference is that the particle size decreases for the doped samples as compared to the pure samples at corresponding temperatures. The reason for that is due to introduction of large amount of foreign particles into the crystal lattice causing strain within the lattice and leading to lattice distortion, which results in a decrease in crystallinity of the material.

The ionic radii of $\mathrm{Fe}^{2+}$ and $\mathrm{Fe}^{3+}$ are different from that of $\mathrm{Zn}^{2+}$. The ionic radii of $\mathrm{Fe}^{2+}, \mathrm{Fe}^{3+}$ and $\mathrm{Zn}^{2+}$ are $0.078 \mathrm{~nm}, 0.068 \mathrm{~nm}$ and $0.074 \mathrm{~nm}$, respectively. If $\mathrm{Fe}$ ions exist in $\mathrm{ZnO}$ mainly in the form of $\mathrm{Fe}^{2+}$, due to larger ionic radius of $\mathrm{Fe}^{2+}$ ion than that of $\mathrm{Zn}^{2+}$, it will lead to compression strain and, as a result, particle size increases [22]. On the other hand, if $\mathrm{Fe}$ ions exist in $\mathrm{ZnO}$ mainly in the form of $\mathrm{Fe}^{3+}$, due to smaller ionic radius of $\mathrm{Fe}^{3+}$ ion than that of $\mathrm{Zn}^{2+}$, it will lead to tensile strain and, as a result, particle size decreases [23]. Therefore, it is reported that $\mathrm{Fe}^{2+}$ and $\mathrm{Fe}^{3+}$ ions 


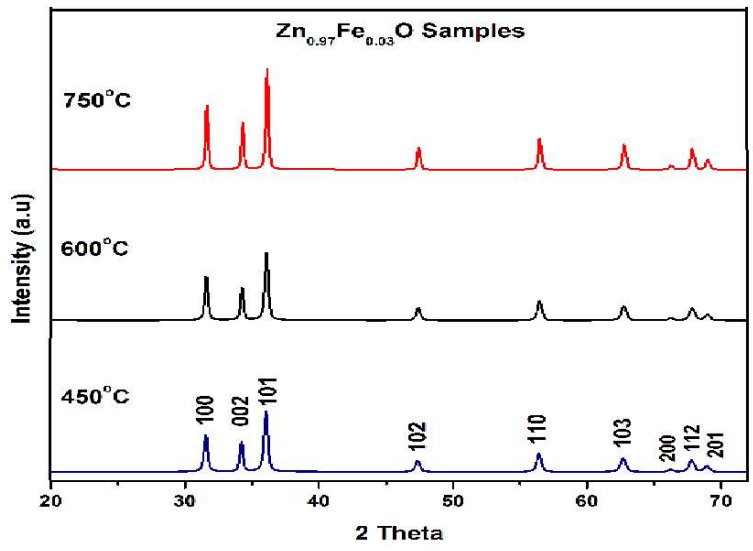

Fig. 2. XRD patterns of $\mathrm{Zn}_{0.97} \mathrm{Fe}_{0.03} \mathrm{O}$ nanoparticles calcined at $450{ }^{\circ} \mathrm{C}, 600{ }^{\circ} \mathrm{C}$ and $750{ }^{\circ} \mathrm{C}$.

may coexist which requires further investigation. For maintaining charge neutrality and to substitute $\mathrm{Zn}^{2+}$ ionic sites, the valence of $\mathrm{Fe}$ ion should be +2 . The ionic radius of $\mathrm{Fe}^{2+}$ is larger than that of $\mathrm{Zn}^{2+}$ whereas that of $\mathrm{Fe}^{3+}$ is smaller. Therefore, it can be inferred that $\mathrm{Fe}^{2+}$ and $\mathrm{Fe}^{3+}$ ions coexist and are expected to distort the lattice structure for holding charge neutrality. So, in order to incorporate the $\mathrm{Fe}$ ions, crystal lattice of $\mathrm{ZnO}$ contracts or expands depending on the nature of the ion. So, all these factors lead to distortion or strain in the material and also produce defects which in turn affect the properties of the material.

Table 1. Lattice parameters of pure $\mathrm{ZnO}$ nanoparticles calcined at $450{ }^{\circ} \mathrm{C}, 600{ }^{\circ} \mathrm{C}$ and $750{ }^{\circ} \mathrm{C}$.

\begin{tabular}{ccccc}
\hline $\begin{array}{c}\text { Calcination tem- } \\
\text { perature }\left[{ }^{\circ} \mathrm{C}\right]\end{array}$ & $\begin{array}{c}\text { Crystallite } \\
\text { size D }[\mathrm{nm}]\end{array}$ & $\begin{array}{c}\mathrm{d}_{101} \\
{[\lambda]}\end{array}$ & \multicolumn{2}{c}{ Lattice constant } \\
\cline { 5 - 6 } & $\mathrm{a}[\AA]$ & $\mathrm{c}[\AA]$ \\
\hline 450 & $31 \mathrm{~nm}$ & 2.4874 & 3.247 & 5.303 \\
600 & $33 \mathrm{~nm}$ & 2.4854 & 3.244 & 5.299 \\
750 & $42 \mathrm{~nm}$ & 2.4881 & 3.248 & 5.304 \\
\hline
\end{tabular}

\subsection{Scanning electron microscopy (SEM) analysis}

The morphology of pure and Fe-doped samples was observed by using a scanning electron microscope (SEM). Fig. 3 shows SEM images of pure $\mathrm{ZnO}$ nanoparticles calcined at $450{ }^{\circ} \mathrm{C}, 600{ }^{\circ} \mathrm{C}$ and $750{ }^{\circ} \mathrm{C}$, respectively. The SEM images confirm that
Table 2. Lattice parameters of $\mathrm{Zn}_{0.97} \mathrm{Fe}_{0.03} \mathrm{O}$ nanoparticles calcined at $450{ }^{\circ} \mathrm{C}, 600{ }^{\circ} \mathrm{C}$ and $750{ }^{\circ} \mathrm{C}$.

\begin{tabular}{ccccc}
\hline $\begin{array}{c}\text { Calcination tem- } \\
\text { perature }\left[{ }^{\circ} \mathrm{C}\right]\end{array}$ & $\begin{array}{c}\text { Crystallite } \\
\text { size D }[\mathrm{nm}]\end{array}$ & \multicolumn{2}{c}{$\mathrm{d}_{101}$} & \multicolumn{2}{c}{ Lattice constant } \\
\cline { 4 - 5 } & $29 \mathrm{~nm}$ & 2.4887 & 3.248 & 5.305 \\
\hline 450 & $29 \mathrm{~nm}$ & $\mathrm{a}]$ \\
600 & $32 \mathrm{~nm}$ & 2.4861 & 3.245 & 5.300 \\
750 & $38 \mathrm{~nm}$ & 2.4834 & 3.241 & 5.294 \\
\hline \hline
\end{tabular}

all the samples are in nano range which is in good agreement with the particle size calculation using the XRD technique. It is clearly seen that the particles are spherical in shape. Further, it is clear that the particle size goes on increasing with an increase in calcination temperature.

Similarly, Fig. 4 shows SEM images of Fedoped $\mathrm{ZnO}$ nanoparticles calcined at $450{ }^{\circ} \mathrm{C}$, $600{ }^{\circ} \mathrm{C}$ and $750{ }^{\circ} \mathrm{C}$, respectively. All the samples are composed of particles in nano range which are spherical in shape as clearly seen from the SEM images. Further, it is clear that the particle size goes on increasing with an increase in calcination temperature. Comparing Fig. 3 and Fig. 4, the difference in particle size is clearly visible and again in good agreement with the XRD calculations.

Fig. 5 shows energy dispersive $X$-ray spectra (EDS) of pure and Fe-doped $\mathrm{ZnO}$ nanoparticles which confirm the elemental composition of the synthesized nanoparticles (undoped and doped). The EDS analysis confirms the presence of $\mathrm{Zn}, \mathrm{O}$ and $\mathrm{Fe}$ in the doped sample with no other impurity element.

Fig. 5a to Fig. 5c show the EDS spectra of pure $\mathrm{ZnO}$ samples calcined at $450{ }^{\circ} \mathrm{C}, 600{ }^{\circ} \mathrm{C}$ and $750{ }^{\circ} \mathrm{C}$, respectively. The EDS spectra indicate that the synthesized pure $\mathrm{ZnO}$ sample mainly contains $\mathrm{Zn}$ and $\mathrm{O}$ elements. The EDS spectral peak of $\mathrm{O}$ appears at $0.5 \mathrm{keV}$ whereas $\mathrm{Zn}$ appears at $1 \mathrm{keV}$, $8.6 \mathrm{keV}$ and $9.5 \mathrm{keV}$ in all three samples. Fig. 5d shows the EDS spectrum of Fe-doped $\mathrm{ZnO}$ sample calcined at $600{ }^{\circ} \mathrm{C}$. The EDS spectrum indicates that the synthesized Fe-doped sample mainly contains Fe, Zn, and O elements. The EDS spectral peak of $\mathrm{O}$ appears at $0.5 \mathrm{keV}, \mathrm{Zn}$ appears at $1 \mathrm{keV}$, $8.6 \mathrm{keV}$ and $9.5 \mathrm{keV}$, while Fe signal appears at $0.7 \mathrm{keV}, 6.4 \mathrm{keV}$ and $7.2 \mathrm{keV}$. 


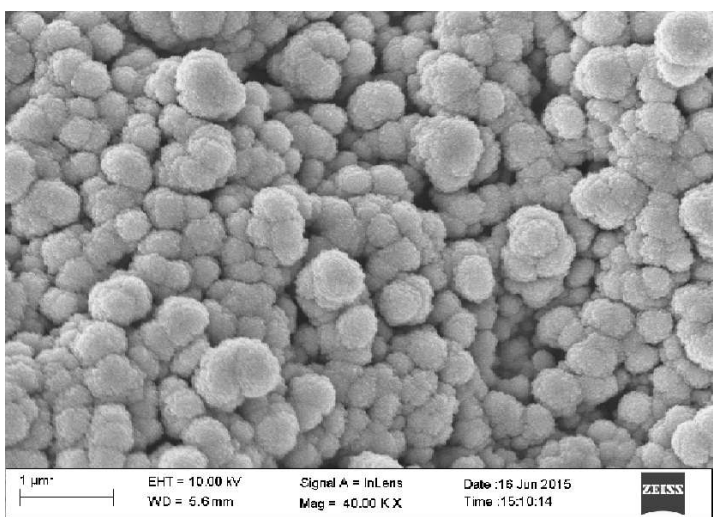

(a)

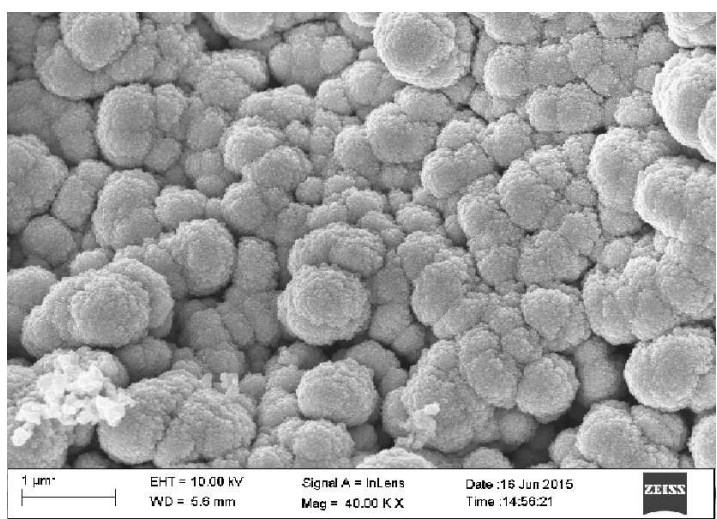

(b)

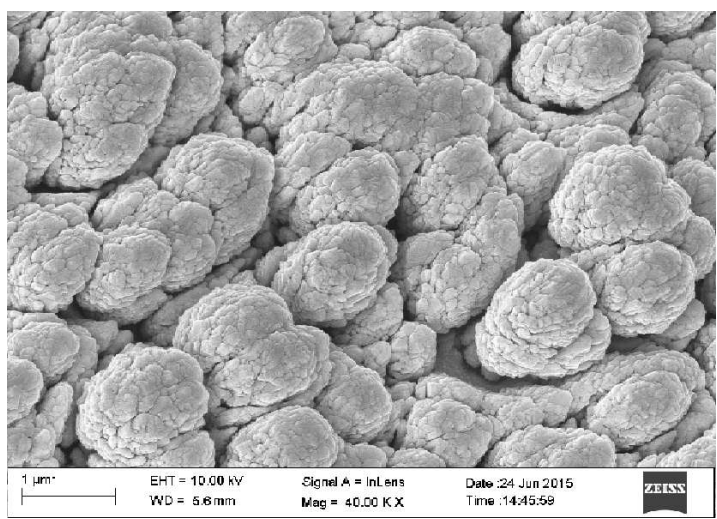

(c)

Fig. 3. SEM images of pure $\mathrm{ZnO}$ nanoparticles calcined at (a) $450{ }^{\circ} \mathrm{C}$, (b) $600{ }^{\circ} \mathrm{C}$ and (c) $750{ }^{\circ} \mathrm{C}$.

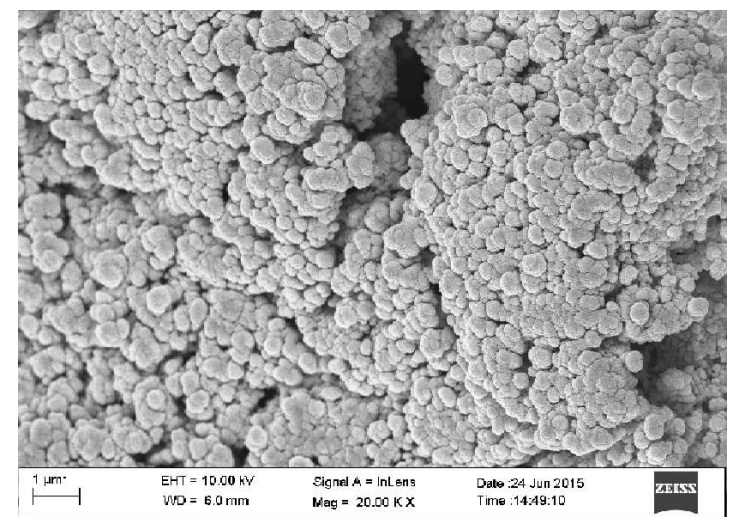

(a)

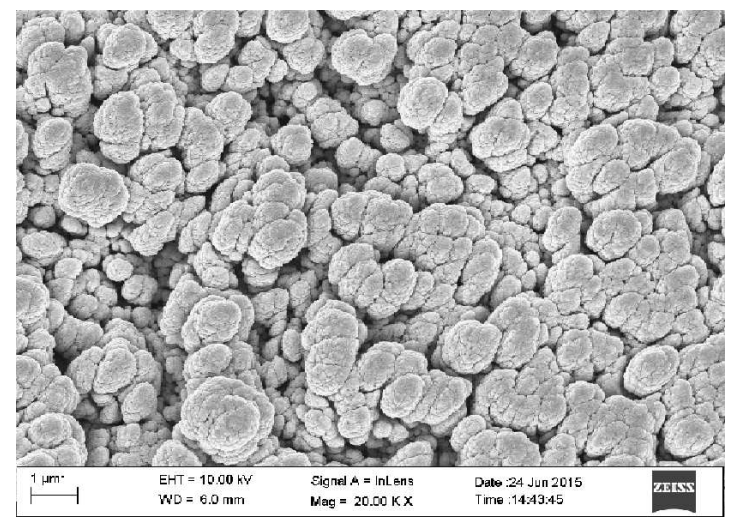

(b)

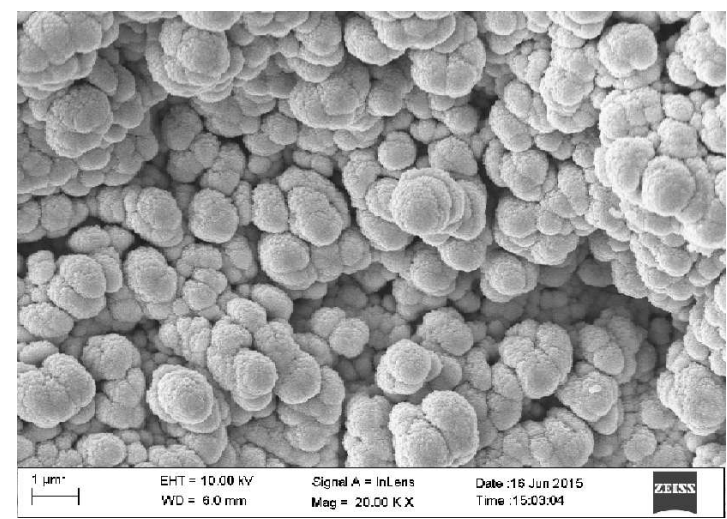

(c)

Fig. 4. SEM images of Fe-doped $\mathrm{ZnO}$ nanoparticles calcined (a) $450{ }^{\circ} \mathrm{C}$, (b) $600{ }^{\circ} \mathrm{C}$ and (c) $750{ }^{\circ} \mathrm{C}$.
The $\mathrm{Zn}$ ions concentration (wt.\%) was found to be approximately $92.01 \%, 91.69 \%$ and $91.51 \%$ for samples calcined at $450{ }^{\circ} \mathrm{C}, 600^{\circ} \mathrm{C}$ and $750{ }^{\circ} \mathrm{C}$, respectively, in pure $\mathrm{ZnO}$ samples as highlighted in Table 3. Fe ions concentration was found to be
$2.18 \%$ for Fe-doped samples calcined at $600{ }^{\circ} \mathrm{C}$. The EDS results further verify the XRD results, which reveal that $\mathrm{Fe}$-doped $\mathrm{ZnO}$ diluted magnetic semiconductor was successfully synthesized by the chemical precipitation method. 


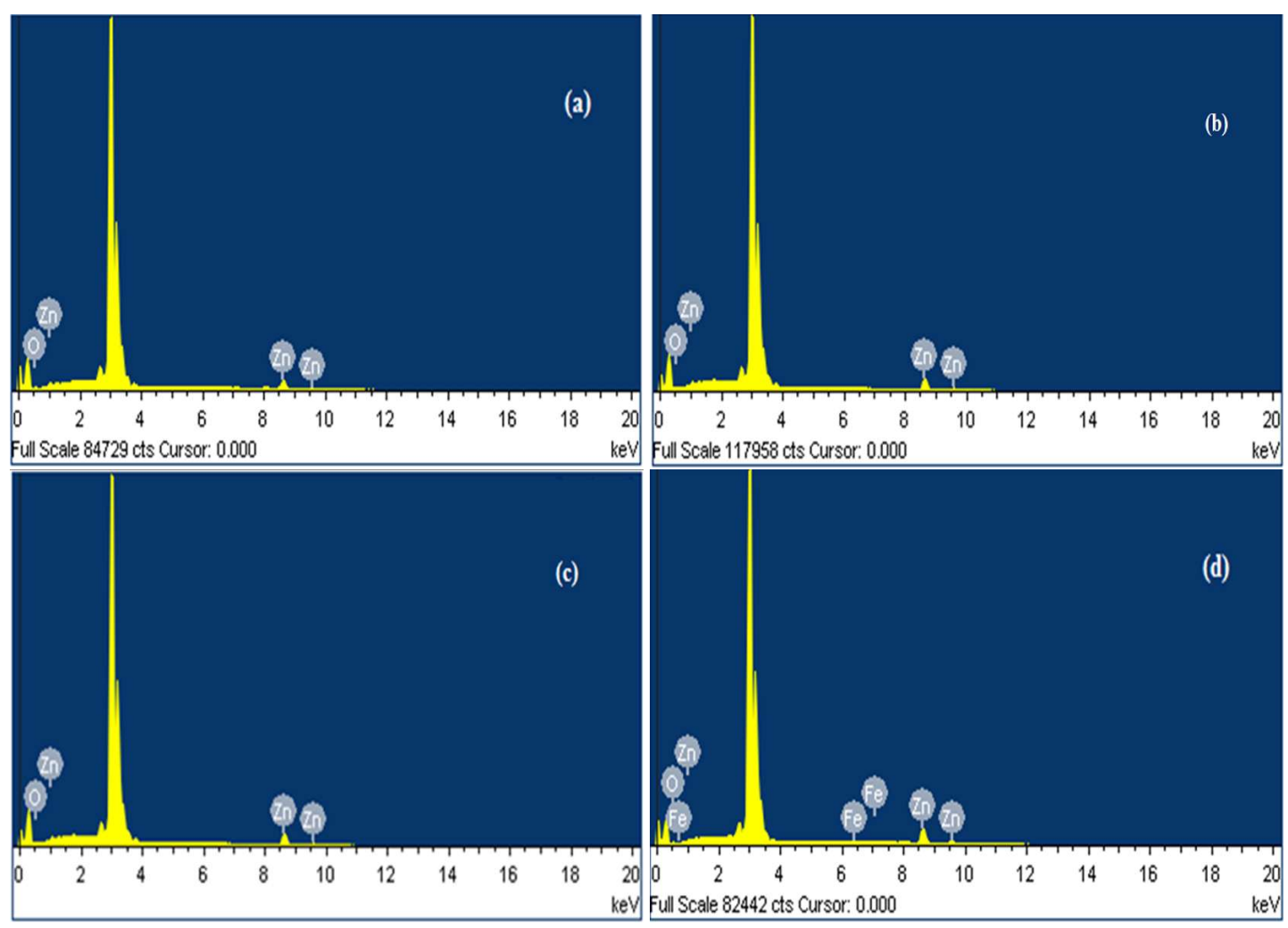

Fig. 5. X-ray energy dispersive spectrometry (EDS) spectra of (a-c) pure $\mathrm{ZnO}$ sample calcined at $450{ }^{\circ} \mathrm{C}, 600{ }^{\circ} \mathrm{C}$ and $750{ }^{\circ} \mathrm{C}$ and (d) $\mathrm{Zn}_{0.97} \mathrm{Fe}_{0.03} \mathrm{O}$ sample calcined at $600{ }^{\circ} \mathrm{C}$.

Table 3. EDAX data of pure $\mathrm{ZnO}$ nanoparticles.

\begin{tabular}{ccc}
\hline $\begin{array}{c}\text { Calcination temperature } \\
{\left[{ }^{\circ} \mathrm{C}\right]}\end{array}$ & $\begin{array}{c}\mathrm{Zn} \\
{[\%]}\end{array}$ & $\begin{array}{c}\mathrm{O} \\
{[\%]}\end{array}$ \\
\hline \hline 450 & 92.01 & 7.99 \\
600 & 91.69 & 8.31 \\
750 & 91.51 & 8.49 \\
\hline
\end{tabular}

\subsection{Optical absorption study}

Results for pure and doped $\mathrm{ZnO}$ nanoparticles were compared by using the UV-Vis absorption spectroscopy. The band gap of semiconductor nanoparticles changes with a change in particle size. The UV-Vis absorption study of pure and Fe-doped $\mathrm{ZnO}$ nanoparticles samples has been carried out over the wavelength range of $300 \mathrm{~nm}$ to $800 \mathrm{~nm}$. Fig. 6a shows the absorption spectra of the pure $\mathrm{ZnO}$ nanoparticles with the absorption peaks at $388 \mathrm{~nm}, 392 \mathrm{~nm}$ and $398 \mathrm{~nm}$ for calcination temperatures of $450{ }^{\circ} \mathrm{C}$,
$600{ }^{\circ} \mathrm{C}$ and $750{ }^{\circ} \mathrm{C}$, respectively. Similarly, Fig. $6 \mathrm{~b}$ shows the absorption spectra of the Fe-doped $\mathrm{ZnO}$ nanoparticles with the absorption peaks at $384 \mathrm{~nm}$, $389 \mathrm{~nm}$, and $395 \mathrm{~nm}$ for calcination temperatures of $450{ }^{\circ} \mathrm{C}, 600^{\circ} \mathrm{C}$ and $750{ }^{\circ} \mathrm{C}$, respectively.

The value of the absorbance is dependent on the various factors, such as size of particles, flaws or defects in grain structure and oxygen deficiency. Lower band gap value $(\mathrm{Eg})$ of pure and doped $\mathrm{ZnO}$ sample compared to bulk $\mathrm{ZnO}(3.39 \mathrm{eV})$ might be due to the presence of oxygen vacancy defects, which is in good agreement with the Eg value determined in the literature [24, 25]. From Table 4 and Table 5, it is seen that the band gap energy decreases with the increase in calcination temperature due to the increase in the particle size as has also been evident from the XRD results.

In contrast to pure $\mathrm{ZnO}$, an increase in the value of band gap energy in doped $\mathrm{ZnO}$ nanoparticles is due to the sp-d spin exchange interaction between 

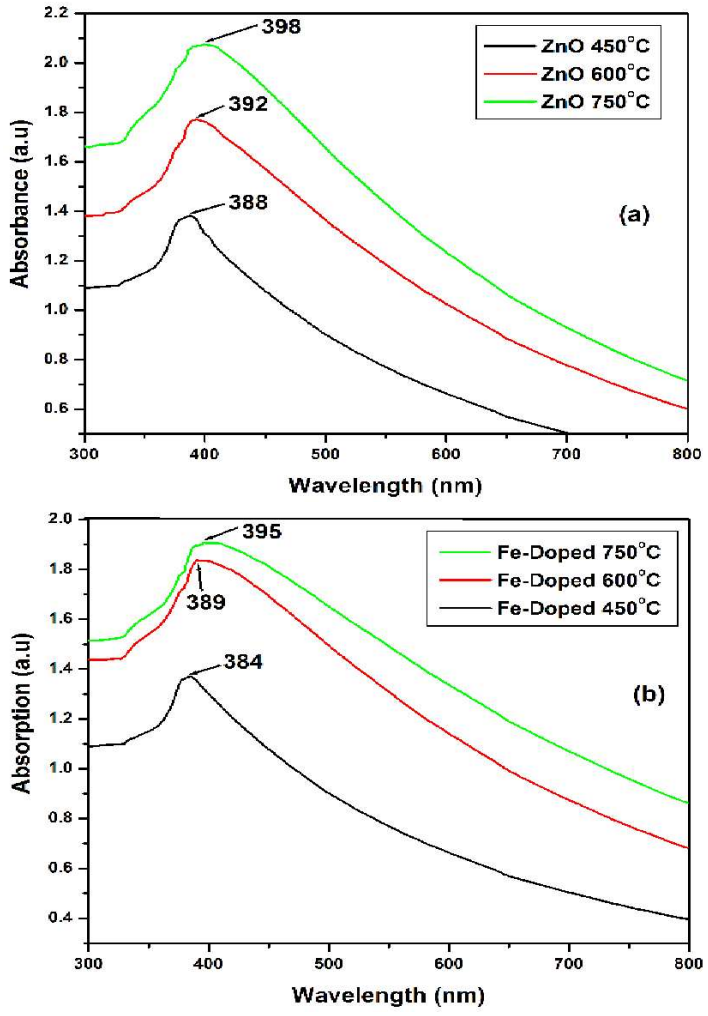

Fig. 6. UV-Vis absorption spectra of (a) pure $\mathrm{ZnO}$ (b) $\mathrm{Zn}_{0.97} \mathrm{Fe}_{0.03} \mathrm{O}$ nanoparticles calcined at $450{ }^{\circ} \mathrm{C}$, $600{ }^{\circ} \mathrm{C}$ and $750{ }^{\circ} \mathrm{C}$.

localized $\mathrm{d}$ electron and band electrons of doped transition metal ions substituting the vacancy of cation. The observed increase in value of $\mathrm{Eg}$ with transition metal ion doping could be mainly due to Fe incorporation at substitutional or/and interstitial sites of wurtzite structure of $\mathrm{ZnO}$.

Table 4. Optical parameters of pure $\mathrm{ZnO}$ nanoparticles calcined at $450{ }^{\circ} \mathrm{C}, 600^{\circ} \mathrm{C}$ and $750{ }^{\circ} \mathrm{C}$.

\begin{tabular}{ccc}
\hline $\begin{array}{c}\text { Calcination tem- } \\
\text { perature }\left[{ }^{\circ} \mathrm{C}\right]\end{array}$ & $\begin{array}{c}\text { Absorption } \\
\text { wavelength } \lambda[\mathrm{nm}]\end{array}$ & $\begin{array}{c}\text { Band gap energy } \\
(\mathrm{Eg}=\mathrm{hc} / \lambda)[\mathrm{eV}]\end{array}$ \\
\hline \hline 450 & 388 & 3.20 \\
600 & 392 & 3.17 \\
750 & 398 & 3.12 \\
\hline
\end{tabular}

\subsection{Vibrating sample magnetometer (VSM) analysis}

The room temperature $\mathrm{M}-\mathrm{H}$ curves of the $\mathrm{Zn}_{0.97} \mathrm{Fe}_{0.03} \mathrm{O}$ nanoparticles calcined at different
Table 5. Optical parameters of $\mathrm{Zn}_{0.97} \mathrm{Fe}_{0.03} \mathrm{O}$ nanoparticles calcined at $450{ }^{\circ} \mathrm{C}, 600{ }^{\circ} \mathrm{C}$ and $750{ }^{\circ} \mathrm{C}$.

\begin{tabular}{ccc}
\hline $\begin{array}{c}\text { Calcination tem- } \\
\text { perature }\left[{ }^{\circ} \mathrm{C}\right]\end{array}$ & $\begin{array}{c}\text { Absorption } \\
\text { wavelength } \lambda[\mathrm{nm}]\end{array}$ & $\begin{array}{c}\text { Band gap energy } \\
(\mathrm{Eg}=\mathrm{hv} / \lambda)[\mathrm{eV}]\end{array}$ \\
\hline \hline 450 & 384 & 3.23 \\
600 & 389 & 3.19 \\
750 & 395 & 3.15 \\
\hline
\end{tabular}

temperatures in the magnetic field ranging from $0 \mathrm{kOe}$ to $\pm 20 \mathrm{kOe}$, obtained from VSM measurements are shown in Fig. 7. Magnetic parameters of all samples are summarized in Table 6. Fig. 7a and Fig. 7b show M-H curves for Fe-doped sample calcined at $450{ }^{\circ} \mathrm{C}, 600{ }^{\circ} \mathrm{C}$ and $750{ }^{\circ} \mathrm{C}$. From Fig. 7a, it can be observed that the sample calcined at $450{ }^{\circ} \mathrm{C}$ has very low coercivity and remanence whereas its magnetization saturation is high. On the other hand, it is observed from Fig. $7 \mathrm{~b}$ that with an increase in calcination temperature, magnetic saturation decreases whereas both coercivity and remanence of Fe-doped sample increase. The magnitude of thermal vibrations of atoms increases with the increase in temperature. The increase in thermal atomic motions neutralizes the coupling forces between the adjacent atomic dipole moments and it causes misalignment of some dipoles, irrespectively of external field. This results in a decrease in magnetic saturation.

So far, several reasons have been discussed to explain the origin of ferromagnetism and still this subject is controversial. One of the theories proposed that room temperature ferromagnetism is exhibited due to various intrinsic and extrinsic phenomena. Intrinsic phenomenon results from exchange interaction, and extrinsic phenomenon occurs due to formation of clusters or secondary phases of dopant semiconductor atoms [26].

In our study, the XRD and EDS results showed that dopant ions are successfully incorporated in the $\mathrm{Zn}$ wurtzite lattice without formation of any secondary phases and metallic clusters. However, there is a possibility of existence of secondary phases in the samples although they were not identified in our case. Therefore, let us consider all impurity phases that might be present 
Table 6. Magnetic properties of $\mathrm{Zn}_{0.97} \mathrm{Fe}_{0.03} \mathrm{O}$ nanoparticles.

\begin{tabular}{cccc}
\hline $\begin{array}{c}\mathrm{Zn}_{0.97} \mathrm{Fe}_{0.03} \mathrm{O} \\
{\left[{ }^{\circ} \mathrm{C}\right]}\end{array}$ & $\begin{array}{c}\text { Coercivity } \\
\mathrm{Hc}(\mathrm{Oe})\end{array}$ & $\begin{array}{c}\text { Remanent } \\
\text { magnetization Mr [emu/g] }\end{array}$ & $\begin{array}{c}\text { Magnetization } \\
\text { sation Ms [emu/g] }\end{array}$ \\
\hline \hline 450 & $15 \mathrm{Oe}$ & $3.05 \times 10^{-4}$ & 0.234 \\
600 & $42 \mathrm{Oe}$ & $3.75 \times 10^{-4}$ & 0.027 \\
750 & $363 \mathrm{Oe}$ & $16.9 \times 10^{-4}$ & 0.006 \\
\hline
\end{tabular}

in the samples and discuss about their ferromagnetic properties. Possible Fe-based oxides that might be present in $\mathrm{Fe}$-doped samples are $\mathrm{FeO}$ and $\mathrm{Fe}_{2} \mathrm{O}_{3}, \mathrm{Fe}_{3} \mathrm{O}_{4}$ and $\mathrm{ZnFe}_{2} \mathrm{O}_{4}$. Secondary phases, such as $\mathrm{FeO}$ and $\mathrm{Fe}_{2} \mathrm{O}_{3}$ are anti-ferromagnetic at Neel temperature of $198 \mathrm{~K}$ and $963 \mathrm{~K}$, respectively [27, 28]. Similarly, $\mathrm{ZnFe}_{2} \mathrm{O}_{4}$ phase is antiferromagnetic and can be excluded as the origin of ferromagnetism in our samples. In contrast to this, $\mathrm{Fe}_{3} \mathrm{O}_{4}$ phase is ferromagnetic but at Curie temperature of approximately $858 \mathrm{~K}$ [29]. Therefore, it is reasonable to conclude that the presence of ferromagnetic behavior in our samples is due to intrinsic coupling between the atoms of doped materials but not due to the presence of metallic clusters or secondary phases.

However, there are certain studies which claim that ferromagnetic behavior in transition metaldoped $\mathrm{ZnO}$ is correlated with defects such as oxygen or zinc vacancies [30-32]. Further, in some studies, the correlation between intrinsic defects such as oxygen or $\mathrm{Zn}$ vacancies and magnetism is also discussed [33, 34]. Karmakar et al. [35] investigated the origin of ferromagnetism in Fe-doped $\mathrm{ZnO}$ using ESR and Mössbauer spectroscopy. The analysis revealed that the $\mathrm{Fe}$ ions are present in both $\mathrm{Fe}^{2+}$ and $\mathrm{Fe}^{3+}$ valence states.

The presence of uncoupled $\mathrm{Fe}^{3+}$ ions is possibly due to hole doping in the system, which is caused by cation (i.e. $\mathrm{Zn}$ ) vacancies. Therefore, once again it is concluded that the ferromagnetism observed in our $\mathrm{Zn}_{0.97} \mathrm{Fe}_{0.03} \mathrm{O}$ sample was due to the presence of $\mathrm{Fe}$ atoms in the form of $\mathrm{Fe}^{2+}$ and $\mathrm{Fe}^{3+}$ ions.

\section{Conclusions}

In our investigations, pure $\mathrm{ZnO}$ and $\mathrm{Fe}$-doped $\mathrm{ZnO}$ nanoparticles calcined at $450{ }^{\circ} \mathrm{C}, 600{ }^{\circ} \mathrm{C}$ and
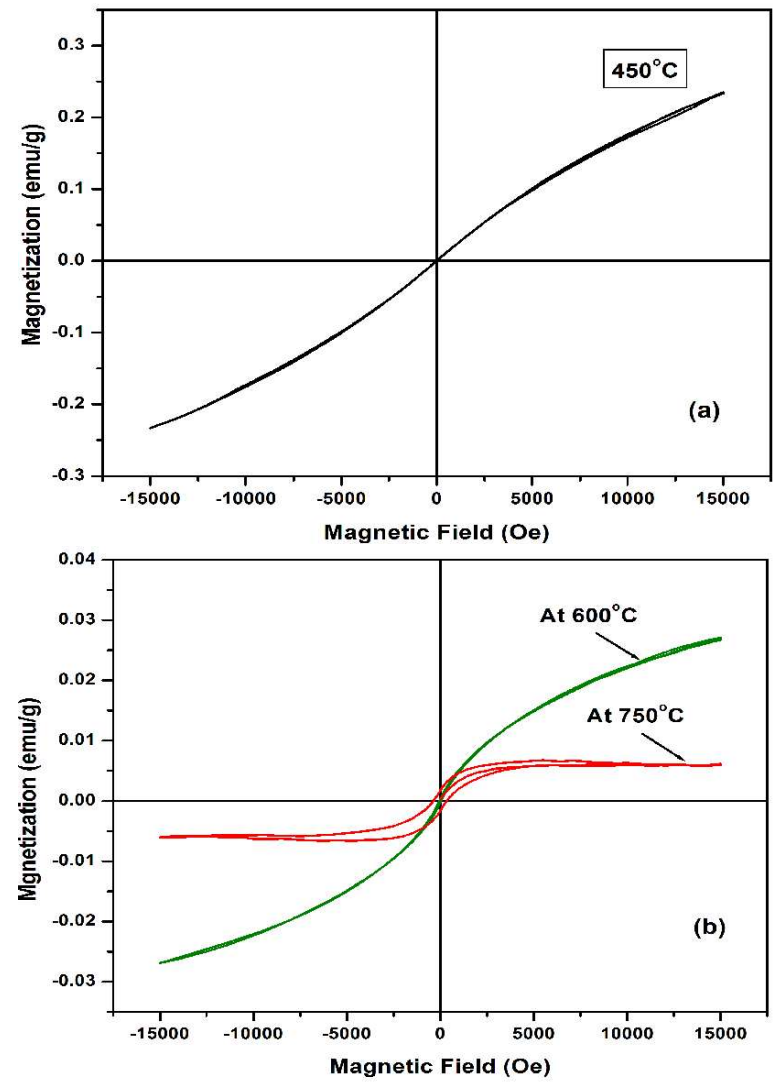

Fig. 7. Room temperature $\mathrm{M}-\mathrm{H}$ curve of $\mathrm{Zn}_{0.97} \mathrm{Fe}_{0.03} \mathrm{O}$ nanoparticles calcined at (a) $450{ }^{\circ} \mathrm{C}$, (b) $600{ }^{\circ} \mathrm{C}$ and $750{ }^{\circ} \mathrm{C}$ calcination temperature.

$750{ }^{\circ} \mathrm{C}$ were successfully synthesized through simple co-precipitation technique. X-ray diffraction pattern analysis confirms the formation of hexagonal wurtzite structure of $\mathrm{ZnO}$ with no evidence of any phase segregation for all samples. XRD patterns also reveal that the quality of crystal formation and particle size is sensitive to the calcination temperature. Both crystallinity and particle size increase with an increase in calcination temperature. UV-absorption spectrum shows red shift in wavelength for the sample calcined at higher 
temperature as compared to the sample calcined at lower temperature. Therefore, the band gap energy decreases with an increase in calcination temperature. Further, $\mathrm{M}-\mathrm{H}$ curves for Fe-doped $\mathrm{ZnO}$ diluted magnetic semiconductor shows that room temperature ferromagnetism is also very much susceptible to calcination temperature. At lower temperature $\left(450{ }^{\circ} \mathrm{C}\right)$, the sample is feebly ferromagnetic with very low coercivity and remanence but high magnetic saturation. On the other hand, at $600{ }^{\circ} \mathrm{C}$ and $750{ }^{\circ} \mathrm{C}$ the sample shows proper S-shaped $\mathrm{M}-\mathrm{H}$ curves which confirms its ferromagnetic behavior. Also, both coercivity and remanence increase with calcination temperature but magnetic saturation decreases as compared to the sample calcined at $450{ }^{\circ} \mathrm{C}$.

Therefore, we conclude that the structural, opti$\mathrm{cal}$ and magnetic properties of pure and doped $\mathrm{ZnO}$ nanoparticles can be controlled by varying calcination temperature.

\section{References}

[1] Ling Z., Leoch C., Freer R., J. Eur. Ceram. Soc., 21 (2001), 1977.

[2] Hsu C.Y., Ku T.F., Huang Y.M., J. Eur. Ceram. Soc., 28 (2008), 3065.

[3] Kumar S.S., Venkateswarlu P., Rao V.R., Rao G.N., Int. Nano Lett., 3 (30) (2013), 2345.

[4] Wolf S.A., Awschalom D.D., Buhrman R.A., Daughton J.M., Molnar S.V., Roukes M.L., Chichel-Kanova A.Y., Treger D.M., Science, 294 (2001), 1488.

[5] OHno H., Science, 281 (1998), 951.

[6] PRINZ G.A., Science, 282 (1998), 1660.

[7] Ghosh S., Mandal K., J. Magn. Magn. Mater., 322 (2010), 1979.

[8] Wesselinowa J.M., Aposto A.T., J. Appl. Phys., 107 (2010), 053917.

[9] KARMAKAR D., MANDAL S.K., KADAM R.M., Paulose P.L., Rajarajan A.K., NATH T.K., DAS A.K., Dasgupta I., Das G.P., Phys. Rev. B, 75 (2007), 144404.

[10] Mandal S.K., DAS A.K., NATH T.K., KaRMakar D., Satpati B., J. Appl. Phys., 100 (2006), 104315.

[11] Martinez B., Sandiumenge F., Balcells L., ArBiol J., Sibieude F., Monty C., Phys. Rev. B, 72 (2005), 165202.

[12] Duan L.B., Rao G.H., Yu J., Wang Y.C., Solid State Commun., 145 (2008), 525.
[13] Luo J., Liang J.K., LiU Q.L., LiU F.S., Zhang Y., Sun B.J., RAO G.H., J. Appl. Phys., 97 (2005), 086106.

[14] Wang J.B., Huang G.J., Zhong X.L., Sun L.Z., Zhou Y.C., LiU E.H., Appl. Phys. Lett., 88 (2006), 252502.

[15] Jayakumar O.D., Gopalakrishnan I.K., SUDAKAR C., KadAM R.M., Kulshreshtha S.K., $J$. Cryst. Growth, 300 (2007), 358.

[16] Bhuiyan M.R.A., Rahman M.K., Int. J. Precis. Eng. Man., 1 (2014), 10.

[17] Vijayaprasath G., Murugan R., Ravi G., Int. J. ChemTech Res., 6 (2014), 3385.

[18] Khatoon S., Ahmad T., Mater. Sci. Eng. B-Adv., 2 (2012), 325.

[19] Jadhav J., Patange M., Biswas S., Carbon-Sci. Tech., 5 (2013), 269.

[20] Vethanathan S.J.K., Perumal S., Sundar S.M., Koilpillai D.P., Karpagavalli S., Suganthi A., Int. J. Adv. Sc. Tech. Res., 6 (2013), 856.

[21] Faheem A., Shalendra K., Nishati A., Anwar M.S., Heo S.N., Koo B.H., Acta Mater, 60 (2012), 5190.

[22] Linhua X., Xiangyin L., J. Cryst. Growth, 312 (2010), 851.

[23] Wang C., Chen Z., He Y., Li L., Zhang D., Appl. Surf. Sci., 255 (2009), 6881.

[24] Aydin C., Abd El-SadeK M.S., Zheng K., Yahia I.S., Yakuphanoglu F., Opt. Laser Technol., 48 (2013), 447.

[25] Morales A.E., Mora E.S., Pal U., Rev. Mex. Fis., 53 (2007), 18.

[26] Sharma V.K., Varma G.D., Adv. Mat. Lett., 3 (2012), 126.

[27] Wang D., Chen Z.Q., Wang D.D., Cong J., CaO C.Y., TAng Z., HuAng L.R., J. Magn. Magn. Mater., 322 (2010), 3642.

[28] Santos D.A.A., Macedo M.A., Physica B, 407 (2012), 3229.

[29] Lin F., JiAng D.M., MA X.M., Physics B, 405 (2010), 1466.

[30] Cong C.J., Hong J.H., Zhang K.L., Mater. Chem. Phys., 113 (2009), 435.

[31] Xiong Z., LiU X.C., Zhuo S.Y., Yang J.H., Shi E.W., Yan W.S., Appl. Phys. Lett., 99 (2011), 052513.

[32] Ramachandran S., Narayan J., Prater J.T., Appl. Phys. Lett., 88 2006, 242503.

[33] BApPaditya P., GiRi P.K., J. Nanosci. Nanotechno., 11 (2011), 1.

[34] Santara B., Giri P.K., Dhara S., IMAKita K., FUJII M., J. Phys. D Appl. Phys., 47 (2014), 235304.

[35] Karmakar D., Mandal S.K., KadaM R.M., Paulose P.L., RaJarajan A.K., NATH T.K., DAS A.K., Dasgupta I., Das G.P., Phys. Rev. B., 75 (2007), 144404.

Received 2015-12-05 Accepted 2016-04-28 